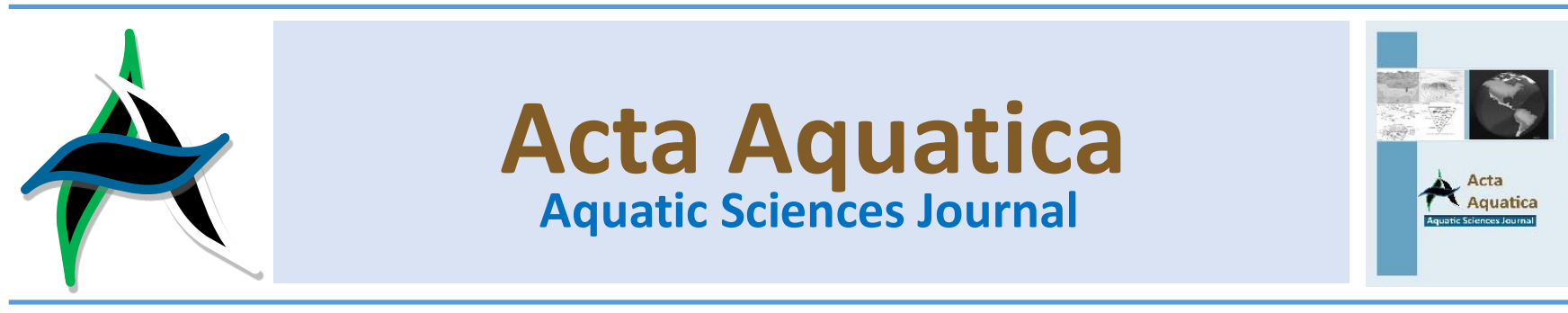

\title{
Efektifitas penambahan vitamin E dalam ransum pakan terhadap tingkat kematangan gonad induk ikan cupang (Betta splendens)
}

\section{Effectiveness of vitamin E addition in diet for gonadal maturity index of Betta splendens broodstock}

\author{
Nurhayati ${ }^{\text {a, * }}$, Azwar Thaib a ${ }^{\text {, dan Irmayani }}{ }^{\text {a }}$ \\ a Program Studi Budidaya Perairan, Fakultas Perikanan, Universitas Abulyatama
}

\begin{abstract}
Abstrak
Ikan cupang (Betta splendens) merupakan salah satu jenis ikan hias air tawar yang memiliki nilai ekonomis tinggi dan potensial untuk dikembangkan. Masalah yang dihadapi oleh pembudidaya ikan cupang adalah sulitnya ditemukan induk yang matang gonad. Salah satu upaya yang dilakukan untuk mengatasi permasalahan ini dengan penambahan vitamin E dalam ransum pakan, sehingga mempercepat tingkat kematangan gonad. Penelitian ini bertujuan untuk mengetahui efisiensi penambahan vitamin $\mathrm{E}$ dalam ransum pakan terhadap tingkat kematangan gonad (TKG), indeks kematangan gonad (IKG), dan fekunditas. Rancangan yang digunakan dalam penelitian ini adalah rancangan acak lengkap ( $R A L$ ) yang terdiri dari 4 perlakuan dan 3 ulangan. Perlakuan yang digunakan adalah kontrol, vitamin $\mathrm{E}$ $0.03 \%, 0.06 \%$ dan $0.1 \%$. Parameter penelitian yang diamati meliputi TKG, IKG, fekunditas dan diameter telur. Hasil penelitian terbaik diperoleh pada perlakuan penambahan vitamin $\mathrm{E} 0,06 \%$ dengan nilai TKG level 4, IKG sebesar 13\%, fekunditas sebanyak 72 butir dan diameter telur berkisar antara 6-7 $\mathrm{mm}$.
\end{abstract}

\begin{abstract}
Betta fish (Betta splendens) is one type of freshwater ornamental fish that had been high economic value and potential to be developed. The problem faced by betta fish farmers were the difficulty of finding mature gonads. One effort was made to overcome this problem with the addition of vitamin $E$ in feed rations, thus speeding up the maturity level of the gonads. This study aims to determine the efficiency of vitamin $E$ addition in feed ration to gonad maturity level (GML), gonado somatic index (GSI), and fecundity. The design used in this study is completely randomized design (CRD) consisting of 4 treatments and 3 replications. The treatment used was control, vitamin E $0.03 \%$, $0.06 \%$ and $0.1 \%$. The observed parameters were GML, GSI, fecundity and egg diameter. The best result was obtained at the addition of vitamin E 0,06\% with GML, GSI, fecundity and egg diameter were level 4, 13\%, 72 eggs and 6-7 $\mathrm{mm}$ respectively.
\end{abstract}

Keywords: Betta splendens; broodstock; gonadal maturity level; gonado somatic index; diet; vitamin $E$

Kata kunci: ikan cupang; indukan; tingkat kematangan gonad; indeks kematangan gonad; pakan; vitamin $E$

\footnotetext{
* Korespondensi: Program Studi Budidaya Perairan, Fakultas Perikanan. Universitas Abulyatama. Jalan Blang Blntang Lama Km. 8,5 Lampoh Keudee, Aceh Besar. Provinsi Aceh, Indonesia. e-mail: nurhayati_perairan@abulyatama.ac.id doi: https://doi.org/10.29103/aa.v5i1.526
}

\section{Pendahuluan}

Ikan cupang (Betta splendens) termasuk dalam famili Anabantidae, ikan ini dapat dipelihara pada lingkungan dengan kondisi oksigen yang minim. Ikan cupang merupakan ikan yang sangat digemari baik dikalangan anak-anak maupun kalangan dewasa karena memiliki bentuk dan warna yang menarik. Salah satu upaya yang dilakukan untuk meningkatkan jumlah benih ikan cupang adalah dengan mempersiapkan atau mempercepat tingkat kematangan gonad (TKG) induk.

TKG menunjukkan tahapan perkembangan gonad ikan. Menurut Effendi (2002) pertambahan berat gonad pada ikan betina sebesar $10-25 \%$ dan ikan jantan sebesar 5-10\% dari berat tubuh, proses pertumbuhan berat gonad umumnya diikuti 
dengan pertambahan besar dan berat sampai batas maksimum ketika terjadi pemijahan. TKG dibagi dalam beberapa tahap diantaranya akan memijah, baru memijah, dan sudah memijah. Tiap TKG bisa diketahui dari pengamatan mikroskopis terhadap ukuran diameter dan penampakan oval, atau irisan histologi dari gonad/ovary.

Selama ini induk ikan cupang yang matang gonad susah ditemukan dipasaran dan membutuhkan waktu yang lama untuk memperoleh kematangan gonad induk ikan cupang. Menurut Utomo (2009), upaya untuk meningkatkan mutu dan jumlah produksi ikan dapat dilakukan melalui perbaikan nutrisi pada pakan induk. Menurut Izquierdo et al. (2001) juga menambahkan bahwa, perbaikan nutrisi pakan induk ikan akan berpengaruh positif tidak hanya pada kualitas telur dan sperma, tetapi juga terhadap mutu dan jumlah benih yang dihasilkan. Upaya yang dilakukan untuk perbaikan nutrisi pada pakan induk yaitu melalui suplementasi vitamin $\mathrm{E}$.

Vitamin E memiliki peranan yang sangat penting dalam menentukan reproduksi ikan, Kebutuhan vitamin $E$ untuk reproduksi berbeda-beda untuk setiap spesies ikan (Syahrizal, 1998). Ikan yang kekurangan vitamin E dapat mempengaruhi penampilan reproduksi, penyebab tidak matang gonad, rendahnya derajat tetas telur, dan kelangsungan hidup benih (Fernandez et al., 1995). Kebutuhan vitamin E dapat bertambah seiring dengan pertambahan jumlah asam lemak dalam pakan. Vitamin E ditambahkan kedalam pakan untuk mempercepat fase pembentukan folikel. Halver (2002) menyebutkan bahwa kebutuhan vitamin E pada rainbow trout adalah $30 \mathrm{mg} / \mathrm{kg}$ pakan, ikan salmon $30 \mathrm{mg} / \mathrm{kg}$ pakan, pada ikan mas $80-100 \mathrm{mg} / \mathrm{kg}$ pakan, pada lele Amerikan $30 \mathrm{mg} / \mathrm{kg}$ pakan, dan Ikan red sea bream memerlukan $42 \mathrm{mg} / \mathrm{kg}$ pakan (Watanabe et al., 1985), ikan bandeng $40 \mathrm{mg} / \mathrm{kg}$ pakan (Prijono et al., 1997). Meskipun penggunaan vitamin $\mathrm{E}$ dalam penelitian pada beberapa spesies pakan telah diketahui, namun penambahan vitamin $E$ untuk induk ikan cupang belum ditemukan sehingga penelitian tentang pemberian vitamin $\mathrm{E}$ dalam ransum pakan untuk mempercepat tingkat kematangan gonad induk ikan cupang perlu dilakukan.

\section{Bahan dan metode}

\subsection{Waktu dan tempat}

Penelitian ini dilaksanakan pada November hingga Desember 2017 di Laboratorium Air Tawar, Fakultas Perikanan Universitas Abulyatama.

\subsection{Bahan dan alat}

Bahan dan alat yang digunakan dalam penelitian ini adalah induk ikan cupang, serok, gayung, selang, klip plastik, filter bag, wadah plastik ukuran 10 liter serta timbangan elektrik.

\subsection{Metode penelitian}

Penelitian ini menggunakan metode eksperimental laboratorium dan rancangan acak lengkap (RAL) yang terdiri dari 4 perlakuan dan 3 kali ulangan. Keempat perlakuan tersebut adalah:

Perlakuan $\mathrm{K}$ : pakan tanpa penambahan vitamin $\mathrm{E}$

Perlakuan A : pakan dengan penambahan vitamin E 0,03\%

Perlakuan B : pakan dengan penambahan vitamin E 0,06\%

Perlakuan C : pakan dengan penambahan vitamin E 0,1\%

\subsection{Prosedur penelitian}

\subsubsection{Persiapan wadah}

Wadah yang digunakan dalam penelitian ini adalah toples plastik berbentuk bulat dengan volume 10 I yang berjumlah 12 buah. Sebelum digunakan terlebih dahulu wadah tersebut dibersihkan dan dikeringkan. Selanjutnya wadah diisi air dengan volume air 8 I dan didiamkan selama 24 jam.

\subsubsection{Persiapan biota uji}

Ikan uji yang digunakan dalam penelitian ini adalah induk ikan cupang sebanyak 72 ekor, dengan jumlah induk jantan 36 ekor dan betina 36 ekor dengan ukuran berkisar antara $3.5-4 \mathrm{~cm}$.

\subsubsection{Persiapan pakan uji}

Pakan uji yang digunakan dalam penelitian ini adalah pakan yang diransum menggunakan dedak, tepung terigu, tepung rebon dan tepung kedelai kemudian ditambahkan vitamin $\mathrm{E}$ sesuai dengan perlakuannya masing-masing. Pakan diberikan sebanyak $3 \%$ dari bobot tubuhnya dengan frekuensi pemberian 3 kali sehari.

\subsection{Parameter yang diamati}

\subsubsection{Tingkat kematangan gonad (TKG)}

Tingkat kematangan gonad diamati secara morfologis dengan memperhatikan warna, bentuk, ukuran panjang dan bobot, perkembangan isi gonad. Gonad dipisahkan antara gonad jantan dan gonad betina, kemudian gonad tersebut diamati secara morfologis yang mengacu kepada Effendi (1979).

\subsubsection{Indeks kematangan gonad (IKG)}

Indeks kematangan gonad dihitung dengan membandingkan bobot gonad $\left(B_{g}\right)$ dengan bobot tubuh ikan $\left(B_{t}\right)$. IKG dihitung dengan menggunakan formula Effendie (1997) sebagai berikut:

$$
I K G=B_{g} / B_{t} \times 100 \%
$$

Keterangan :

IKG = indeks kematangan gonad

$\mathrm{B}_{\mathrm{g}}=$ bobot gonad (gram)

$B_{t}=$ bobot tubuh ikan (gram)

\subsubsection{Fekunditas}

Fekunditas diperkirakan sebagai jumlah telur yang ditemukan dalam ovary pada ikan yang te;ah mencapai TKG III dan IV. Fekunditas total dihitung dengan menggunakan metode sub-contoh bobot gonad atau disebut metode gravimetrik. Fekunditas ikan ditentukan dengan menggunakan metode gravimetric dengan menggunkan formula Effendie (1997):

Keterangan:

$$
\mathrm{F}=\frac{\mathrm{G}}{\mathrm{Q}} \times \mathrm{N}
$$

$F=$ fekunditas (butir)

$\mathrm{G}=$ bobot tubuh (g)

$Q=$ bobot gonad contoh

$\mathrm{N}=$ jumlah telur pada gonad contoh (butir) 


\subsubsection{Diameter telur}

Diameter telur ikan diukur di bawah mikroskop binokuler dengan bantuan mikrometer okuler. Pengukuran dilakukan pada telur-telur yang berada pada tingkat kematangan gonad III dan IV. Diameter telur dihitung menggunakan rumus (Rodriquez et al., 1995):

Keterangan :

$$
D s=\sqrt{D x d}
$$

$\mathrm{Ds}=$ diameter telur sebenarnya $(\mathrm{mm})$

$\mathrm{D}=$ diameter telur terbesar $(\mathrm{mm})$

$\mathrm{d}=$ diameter telur terkecil $(\mathrm{mm})$

\subsection{Analisis data}

Data yang diperoleh dari hasil penelitian dianalisis secara deskriptif, kemudian disajikan dalam bentuk grafik.

\section{Hasil dan pembahasan}

\subsection{Tingkat kematangan gonad (TKG)}

Hasil penelitian menunjukkan bahwa, sampel gonad pada perlakuan $\mathrm{K}$ berkembang hingga tahap TKG II dengan ciri-ciri gonad berukuran kecil dan berwarna putih transparan. Pada perlakuan A, gonad ikan uji berkembang hingga tahap TKG III dengan ciri-ciri perlakuan mulai matang, berukuran lebih besar dan berwarna kuning. Pada perlakuan B gonad ikan uji berkembang hingga tahap TKG IV dengan ciri-ciri ukuran gonad lebih besar dan berwarna kuning terang. Gonad pada perlakuan ini sudah matang dan siap untuk dibuahi. Pada perlakuan $C$ gonad ikan uji berkembang hingga tahap TKG III dengan ciri-ciri perlakuan mulai matang, berukuran lebih besar dan berwarna kuning.

Tingkat kematangan gonad (TKG) terbaik ditemukan pada perlakuan dengan penambahan vitamin E sebesar $0.06 \%$. Hal ini disebabkan oleh kebutuhan vitamin yang diberikan pada pakan sudah memenuhi kebutuhan ikan sehingga dapat memacu kecepatan pencapaian matang gonad. Ketika perkembangan gonad semua proses metabolisme dalam tubuh ikan bertumpu pada pertumbuhan gonadik.

Pertumbuhan gonadik terjadi apabila energi yang digunakan untuk pertumbuhan somatik sudah terpenuhi (Affandi dan Tang, 2002). Selain itu, vitamin E ( $\alpha$-tokoferol) merupakan salah satu unsur nutrient yang harus dipenuhi dalam pakan, karena vitamin E diperlukan sebagai bahan penyusun struktur somatik, gonadik, dan penentu kualitas telur. Vitamin E ini juga berfungsi sebagai antioksidan, sehingga asam lemak tidak jenuh pada posfolipid dalam membran sel terlindungi (Hamre, 2011).

\subsection{Indeks kematangan gonad (IKG)}

Hasil penelitian terhadap indeks kematangan gonad (IKG) selama 60 hari ditampilkan pada Gambar 1 . Indeks kematangan gonad (IKG) terbaik ditemukan pada perlakuan B dengan penambahan vitamin E dalam pakan sebesar $0.06 \%$ dan mampu meningkatkan IKG sebesar $13 \%$. Tingginya IKG pada perlakuan tersebut diduga karena dosis vitamin E yang ditambahkan dalam pakan sudah sesuai dan memenuhi kebutuhan ikan. Hal ini juga selaras dengan penelitian yang dilakukan oleh Yulfiperius et al., (2003) bahwa, penambahan vitamin E dalam pakan sebesar $189,65 \mathrm{mg} / \mathrm{kg}$ pakan dapat meningkatkan kualitas telur ikan patin. Disamping itu, hasil penelitian Napitu et al., (2013) menunjukkan bahwa penambahan vitamin $\mathrm{E}$ dalam pakan buatan sebesar $300 \mathrm{mg} / \mathrm{kg}$ pakan memberikan pengaruh paling baik dalam meningkatkan kematangan gonad ikan nila merah.

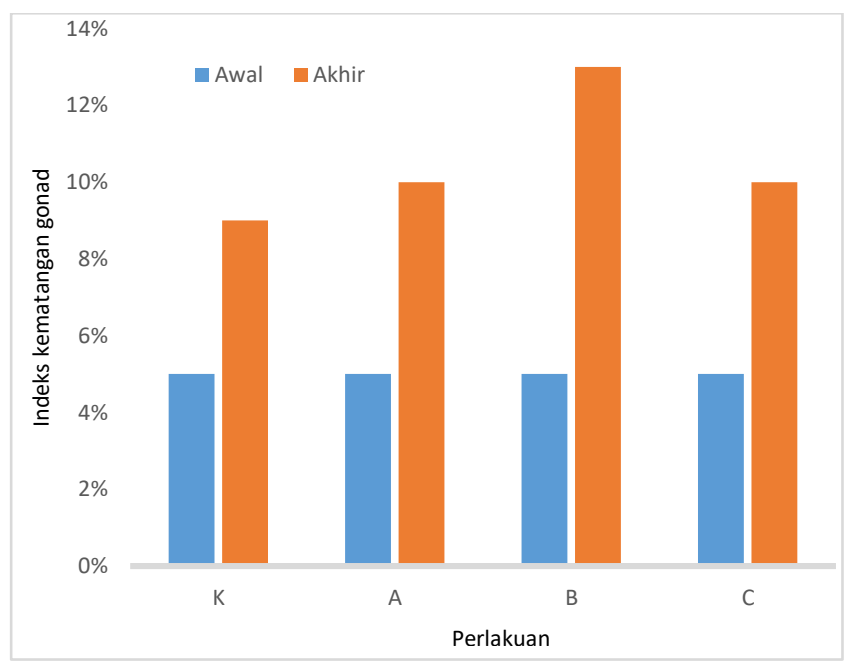

Gambar 1. Indeks kematangan gonad induk ikan cupang.

Rendahnya IKG pada perlakuan $\mathrm{K}$ dan perlakuan A diduga karena lemak yang tedapat dalam ransum pakan tidak mencukupi kebutuhan tubuh ikan. Hal ini diperkuat oleh Takeuchi et al. (1992) bahwa, rendahnya vitamin E dalam pakan dapat menyebabkan kandungan lemak dihati dan diotot berkurang.

\subsection{Fekunditas}

Fekunditas merupakan jumlah telur yang dikeluarkan dalam satu siklus reproduksi. Hasil penelitian menunjukkan tingkat fekunditas hanya ditemukan pada perlakuan B dengan penambahan vitamin $E$ sebesar $0.06 \%$. Jumlah telur yang dikeluarkan pada perlakuan tersebut berjumlah 72 butir. Adanya fekunditas pada perlakuan tersebut diduga karena dipengaruhi oleh kualitas induk betina dan nutrient pakan serta efisiensi pemanfaatanya. Arfah et al. (2013) menyatakan bahwa aktivitas prostaglandin juga diduga berperan dalam pembentukan butirbutir telur. Semakin banyak vitelogenin yang dibawa ke gonad, maka semakin banyak butir-butir telur yang dibentuk dalam gonad. Besarnya nilai fekunditas juga dipengaruhi oleh nilai IKG.

\subsection{Diameter telur}

Hasil dari penelitian menunjukan diameter telur yang terkecil $6,00 \mathrm{~mm}$, sedangkan yang terbesar $7,00 \mathrm{~mm}$ dan diameter telur sebenarnya 0,734847 $\mathrm{mm}$. Diameter telur ikan cupang pada penelitian ini relative besar, kemungkinan disebabkan oleh jumlah telur yang dikeluarkan hanya sedikit. Menurut Diani et al. (2005) diameter telur ikan cupang yang dibuahi berkisar antara 0.90-1.0 mm dan berwarna putih kekuning-kuningan serta menempel pada sarang busa. Diameter telur ikan bervariasi antar spesies maupun antar individu dalam spesies yang sama. Diameter telur ikan berkisar antara 0.25-7.00 $\mathrm{mm}$ (Wooton, 1998).

Diameter telur ada hubungannya dengan fekunditas. Makin banyak telur yang dipijahkan, maka ukuran diameter telurnya makin kecil, demikian pula sebaliknya (Tang dan Affandi, 2001). Hal ini juga dikemukakan oleh Wootton (1998) bahwa ikan yang memiliki diameter telur lebih kecil biasanya mempunyai fekunditas yang lebih banyak, sedangkan yang memiliki diameter telur yang besar cenderung memiliki fekunditas rendah. Semakin besar ukuran diameter telur akan semakin baik, karena dalam telur tersebut tersedia makanan cadangan sehingga larva ikan 
akan dapat bertahan lebih lama. Larva yang berasal dari telur yang besar memiliki keuntungan karena memiliki cadangan kuning telur yang lebih banyak sebagai sumber energi sebelum memperoleh makanan dari luar. Ukuran diameter telur dapat menentukan kualitas yang berhubungan dengan kandungan kuning telur, telur yang berukuran besar juga dapat menghasilkan larva yang berukuran besar. Effendie (1997) menyatakan bahwa semakin berkembang gonad, maka ukuran diameter telur yang ada didalamnya semakin besar sebagai hasil pengendapan kuning telur, hidrasi, dan pembentukan butir-butir minyak.

\section{Kesimpulan}

Hasil penelitian tentang efisiensi penambahan vitamin e dalam ransum pakan terhadap tingkat kematangan gonad induk ikan cupang (Betta splendens) dapat ditarik kesimpulan bahwa penambahan vitamin $E$ dalam ransum pakan dapat mempercepat tingkat kematang gonad. Perlakua B dengan penambahan $0.06 \%$ vitamin E merupakan perlakuan terbaik yang mampu meningkatkan nilai IKG sebesar $13 \%$, fekunditas 72 butir dengan diameter telur berkisar antara 6-7 $\mathrm{mm}$.

\section{Bibliografi}

Arfah, H., Melati, Setiawati, M., 2013. Suplementasi vitamin E dengan dosis berbeda pada pakan terhadap kinerja reproduksi induk betina ikan komet Carassius auratus auratu. Jurnal Akuakultur Indonesia. 12 (1), 14-18.

Diani, S., Mustahal, Pramu, S., 2005. Usaha pembenihan ikan hias cupang (Betta splenders) di Kabupaten Serang. Jurnal Pengkajian dan Pengembangan Teknologi Pertanian. 8 (2), 292-299.

Effendie, M.I., 1997. Metode Biologi Perikanan. Penerbit yayasan dewi sri. Bogor. 112 hal.

Fernandez, P, Izquierdo, M., Robaina, L., Valencia, A., Salhi, M., Jose, M., 1995. Effect of n-3 HUFA level in broodstock diets on egg quality of gilthead sea bream, Sparatus auratus L. Aquaculture. 132, 325-337.

Halver, J.E., 2002. The vitamins. In Halver. J.E. \& Hardy, R. W. (Eds). Fish Nutrition. Academic Press, San Diego CA, USA. P. 61-141.

Hamre, K., 2011. Metabolism, interactions, requirements and functions of vitamin $\mathrm{E}$ in fish. Aquaculuture Nutrition. 17, 98-115.

Izquierdo, M., Fernandez, Tacon, A., 2001. Effect of broodstock nutrition on reproductive performance of fish. Aquaculture. 19, 25-42.

Prijono, A., Sugama, K., Azwar, Z.I., Setiadharma, T., Sutarmat, T., 1997. Implantasi vitamin E untuk memacu pematangan gonad induk ikan bandeng (Chanos chanos, Forskal). Jurnal Penelitian Perikanan Indonesia. 3 (I), 21-28.

Rodriquez, J. N., Oteme, Z.J., Hem, S., 1995. Comparative study of Vitellogenesis of two African catfish Chrysichthys nigrodigitatus and Heterobranchus longifilis (clriidae). Aquat. Living resour. 8, 291-296.
Syahrizal, 1998. Kadar Optimum Vitamin E dalam Pakan Induk Ikan. IPB:Bogor.

Takeuchi, T., Watanabe, K., Satoh, S., Watanabe, T.,1992. Requirement of Grass Carp fingerling for $\alpha$-tocoferol. Nippon Suisan Gakkaishi. 58 (9), 1743-1749.

Tang, U.M., Affandi, R., 2001. Biologi Reproduksi ikan. Pusat Penelitian Kawasan Pantai dan Perairan. Universitas Riau, Pekan Baru. 153 hal.

Utomo, N.P., 2009. Peningkatan mutu reproduksi ikan hias melalui pemberian kombinasi asam lemak esensial dan vitamin E dalam pakan pada ikan uji zebra (Danio rerio). Bogor. Institut Pertanian Bogor.

Watanabe ,T., Koizumi, T., Suzudi, H., Satoh, S., Takeuchi, T., Yoshida, N., Kitada, T., Tsukashima, Y., 1985. Improvement of quality of red sea bream eggs feeding broodstock on a diet containing cuttlefish meal or on raw krill sortly before spawning. Jpn. Soc. Sci. Fish. 51, 15111521.

Wootton, R.J., 1998. Ecology of Teleost Fishes. Kluwer Academic Publihers (Fish and Fisheries Series No. 24), Dordrecht, Netherlands.

Yulfiperius, Mokoginta, Dedi, J., 2003. Pengaruh Kadar Vitamin E dalam Pakan terhadap Kualitas Telur Ikan Patin (Pangasius hypothalmus). IPB: Bogor. 